\title{
E-material Formatting Application Prototype 2.0
}

\author{
Kristine MACKARE, Anita JANSONE, Raivo MACKARS \\ Liepaja university, Liela Street 14, Liepaja, Latvia \\ kristine.mackarediepu.lv, anita.jansonedliepu.lv, \\ raivo.mackars@gmail.com
}

\begin{abstract}
Digital devices provide the most amount of nowadays textual information. Unfortunately, the humans' vision system is not fully adapted to the new reading situation - digital reading model. Screen users are having complaints during and after screen use. Firstly, current recommendations and methodologies for e-material formatting are not appropriate for digital reading. It is based on printed material and is not adapted to e-materials. It increases complains of users. There are developed parameter recommendations for more appropriate and user-centric ematerial formatting. It is developed for e-learners without significant reading and learning limitations and without disabilities but with the possibility to modify. Secondly, based on research, there is no automated process of personalized formatting for e-materials. For automatization of the formatting process, an app is developed to reach the improvement of visual perception faster. It is important to reach a wider range of users and increase the possibility of personalization. Prototype 2.0 is focused on improvements in the application. In the second prototype, PHP7.3 programming language has been used. As it is the server language it is appropriate for this kind of app. The prototype 2.0 focus is to make it accessible and workable on all the most popular formats of ematerials during development and correcting phase of the app development. The significant upgrade is that the app is made in such a way so it could be used with any e-material system not only Moodle. The improved version of the application is focused on visual appearance as prototype 2.0 is planned to use for the alpha testing.
\end{abstract}

Keywords: app prototype, e-learning, e-material, formatting application

\section{Introduction}

Digital devices provide the most amount of nowadays information. According to statistical data, at least $51 \%$ worldwide population uses the internet and digital devices to provide it. In Europe it is more than $87 \%$, and in the EU number is even higher (WEB (a); WEB (b)). Despite the accessibility of the wide range different visual, graphical and audial solutions and materials, textual information still is on the top as popular e-material for everyday use (Khan and Khushdil, 2013).

As it is known, reading from printed materials and screen is different (Myrberg and Wiberg, 2015). The reading research has shown that screen reading is much difficulty (Khan and Khushdil, 2013). A significant part of screen-reading discomfort is based on 
the preference of paper reading and reading experience (Kretzschmar, 2013). Comprehension is worse from the screen (Mangen, 2013).

In nowadays digital reading situation, the reader must cope with a) the constantly growing number of available information sources, b) the different formats in which digital information is presented, c) the varying quality of the information available (Salmerón, et al., 2018). Unfortunately, the humans' vision system is not fully adapted to the new reading situation - digital reading model (Nielsen, 2000).

Screen users are having complaints during and after screen use. The people vision system is adapting for the new visual information perception model, but the human evaluation process is not as fast as technology progress (Webster, 2015). The visual system needs help, as digital reading is the future. Today, $57 \%$ of all two-year-olds in Sweden are using the internet - most of them on a tablet computer (Findahl, 2014).

There are no possibilities to stop the development of devices, and it would not be useful or wise, but there is a need to try to help achieve a more comfortable and healthier screen reading.

\section{Previous work}

\subsection{Literature research and formatting recommendation}

Firstly, current recommendations and methodologies for e-material formatting are not appropriate for digital reading (Mackare and Jansone, 2017). Parameter unambiguity in current recommendations and suggestions for e-materials have been found. Existing ones are based on printed material and is not adapted to e-materials. It increases complains of users. These conclusions are based on an analysis of more than 100 different sources. All variations shortly represented in Table 1.

Followed four basic parameters as font type, font size, line spacing and colour of text and background are chosen for modification use. These are important parameters for content presentation as well as have more possible variations to be used in formatting. Also, this is crucial to affect perception, readability and comprehension. A wider overview can be found in a previous publication (Mackare and Jansone, 2017).

Table 1. Representation of suggested parameters variety

\begin{tabular}{llll} 
& from & to & DRinTS* \\
\hline Font type & Sans Serif & Serif & 23 in 35 \\
\hline Font size & 8.0 & 28.0 & 20 in 17 \\
\hline Line spacing & 0.9 & 2.5 & 13 in 9 \\
\hline Text colour & black & white & 8 in 15 \\
\hline Background colour & white & black & 6 in 11 \\
\hline *Different parameter recommendations in total sources & \\
\hline
\end{tabular}

There are developed parameter recommendations (Table 2) for more appropriate and user-centric e-material formatting. It is developed for e-learners without significant 
reading and learning limitations and without disabilities but with the possibility to modify (Mackare and Jansone, 2019a).

Parameter recommendations have been developed based on theoretical base and practical research. Theoretical base includes people development stages of cognitive and visual development, reading and perception abilities, physiological and psychological capabilities as well as ocular changes during life. Practical research was conducted to discover a subjective preference. (Mackare and Jansone, 2019a).

Table 2. General formatting recommendations for e-material body text parameters

\begin{tabular}{lllll}
$\begin{array}{l}\text { Age } \\
\text { group }\end{array}$ & Font & Font size & $\begin{array}{c}\text { Space between } \\
\text { lines }\end{array}$ & $\begin{array}{c}\text { Text and } \\
\text { background colours }\end{array}$ \\
\hline $3-5 \mathrm{~g}$ & $\begin{array}{c}\text { Verdana* } \\
\text { Arial* }\end{array}$ & $\begin{array}{l}14 \mathrm{pt}^{*} \\
16 \mathrm{pt}^{*}\end{array}$ & $\begin{array}{l}2^{*} \\
2 *\end{array}$ & Black on white* \\
\hline $6-12 \mathrm{~g}$ & Verdana & $12 \mathrm{pt}$ & 2 & Black on white \\
\hline $12-15 \mathrm{~g}$ & Arial & $14 \mathrm{pt}$ & 1,5 & Grey on white \\
\hline $16-25 \mathrm{~g}$ & Veorgia & $16 \mathrm{pt}$ & 1,15 & Black on white \\
\hline & ANR & $14 \mathrm{pt}$ & 1,5 & Grey on white \\
\hline $26-35 \mathrm{~g}$ & Verdana & $12 \mathrm{pt}$ & 1,15 & Black on white \\
\hline & Arial & $12 \mathrm{pt}$ & 1,15 & Grey on white \\
\hline $36-39 \mathrm{~g}$ & Verdana & $14 \mathrm{pt}$ & 1,5 & Black on white \\
\hline & Arial & $14 \mathrm{pt}$ & 1,15 & Grey on white \\
\hline $40-55 \mathrm{~g}$ & Verdana & $14 \mathrm{pt}$ & 1,5 & Black on white \\
\hline & Arial & $14 \mathrm{pt}$ & 1,5 & Grey on white \\
\hline $55+\mathrm{g}$ & Verdana & $14 \mathrm{pt}$ & 1,5 & Black on white \\
\hline & Arial & $16 \mathrm{pt}$ & 1,5 & Black on white \\
\hline $65+\mathrm{g} *$ & Verdana* & $16 \mathrm{pt} *$ & 1,5 & Black on white* \\
\hline & Arial* & $18 \mathrm{pt} *$ & $1,5^{*}$ & $2 *$ \\
\hline
\end{tabular}

*prediction based on all other data

\subsection{Prototype}

Secondly, based on research, there is no automated process of personalized formatting for e-materials. For automatization of the formatting process, an app is developed to reach the improvement of visual perception faster. It is important to reach a wider range of users and increase the possibility of personalization. Have been developed application concept and the first prototype of the application. (Zigunovs et al., 2018; Mackare et al., 2018; Mackare and Jansone, 2019b). 
Application concept is based on literature research (Mackare and Jansone, 2017), developed recommendations for e-material formatting and on the research of users' individual factors and need. It involves such component as an idea of the tool by itself and a vision of design. Three main edges of the app represent the concept: user, interface, and database, as well as collaboration processes between edges and the main idea of the app - text formatting of documents based on user groups. It must give a clear understanding of the application to the programmer what must be done. The app must work for both - e-material creators and e-material users. More detailed concept description is published previously (Zigunovs et al., 2018; Mackare et al., 2018; Mackare and Jansone, 2019b).

Already developed the first version of application prototype gives the overview of the application work to follow implemented working schemes, relationships between main edges and the collaboration process with the user, material and database. For the possibility to give formatting recommendations, application collect necessary data from the user. That is followed by solution finding with a step-by-step recommendation and so-called tree-scheme of users answers and related application responses what gives a recommendation of text formatting and provides it. After the user has tried new formatting of e-material, the application provides a short questionnaire of user feedbacks. An application can be described from four sides: developers, e-material formatting users as readers, e-material creators and researchers. A more detailed description of the application prototype is published previously (Zigunovs et al., 2018; Mackare et al. 2019).

\section{Prototype 2.0}

The application working concept represented on Fig.1.: The raw document (1) is uploaded in the application. The document is going through the formatting process by formatting software (2) and personalized requirements (3). Formatting software includes - all requirements, technical solution, programming, database. Requirements include user needs, personalized formatting, formatting recommendations. After formatting process person get the formatted and personalized document (4). In the database (5) save all data - users' data, users' responses, requirement, formatting recommendations, users accumulated data, data accumulated after the machine learning process. The database is not only storage but also an active process. Formatting software gets data from the database (A). It is data for software improvement and personalized approach of formatting. The formatted and personalized document gives data to database (B). It is users accumulated data after the user has used personalized document - reading time, eye movements, memorizing abilities, user satisfaction, decrease of complains, improvement of ocular functions. Between database and requirements are data transport (C) - personalized requirements and formatting information.

Application prototype is developed on Moodle type platform base, but the significant upgrade is that the app is made with possible transformation and adaptation in such a way so it could be used with any e-material system not only Moodle. It gives a more expansive range of use and for a different environment. 


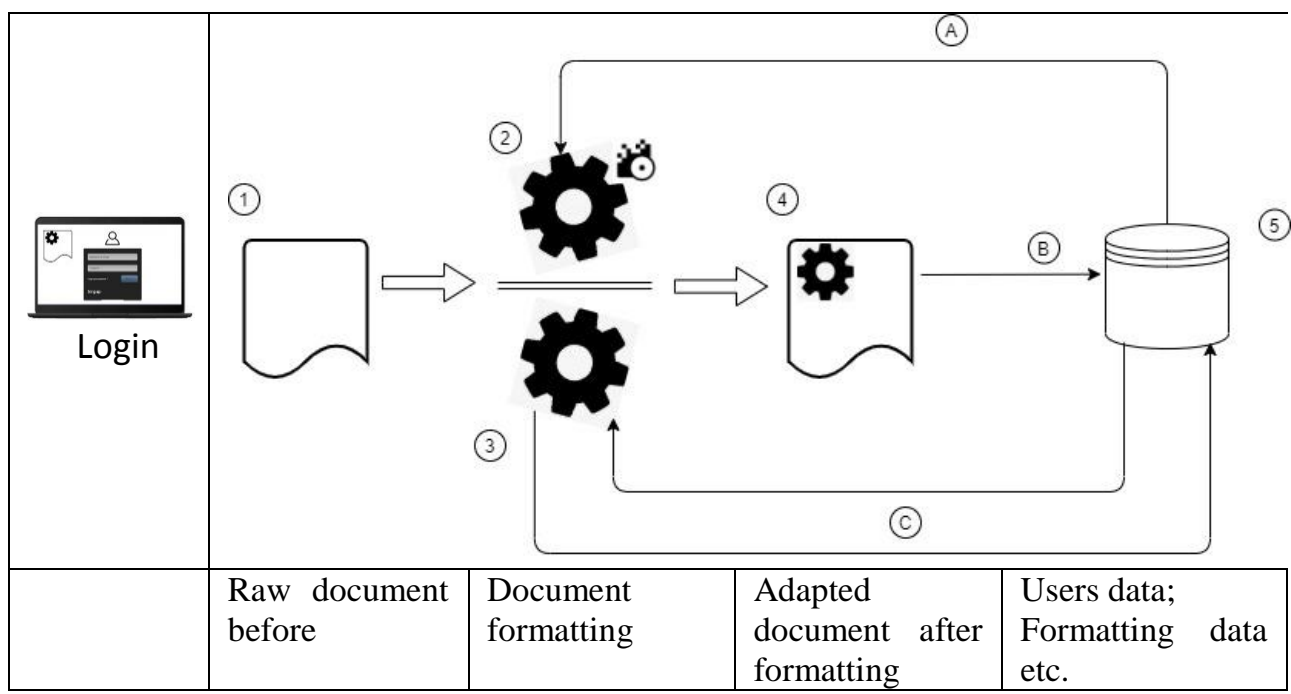

Fig.1. The application concept.

The improved version of the application is focused on visual appearance as prototype 2.0 is planned to use for the alpha testing. It is designed simple but functional.

User interaction and design example of a login screen is shown in Fig.1. Frontpage of the app looks very simply. It has a Log-in option for registered users with full accesses, and more deeply personalised formatting possibilities. Moreover, Sing up the possibility.

Also, it includes questions or tasks which need to be discussed and possible outcomes or solutions (Table 3 ).

Table 3. User design possibilities

\begin{tabular}{|l|l|}
\hline $\begin{array}{l}\text { Possible alternative Login } \\
\text { methods }\end{array}$ & \multicolumn{1}{|c|}{ Outcome } \\
\hline Sing in with Moodle & $\begin{array}{l}\text { This is very important } \\
\text { Should try to develop for version 2.1 }\end{array}$ \\
\hline Sing in with Facebook & $\begin{array}{l}\text { This is important, but not for prototype 2.0 } \\
\text { Must look on this at the later stage }\end{array}$ \\
\hline Sing in with Google+ & $\begin{array}{l}\text { This is important, but not for prototype 2.0 } \\
\text { Must look on this at the later stage }\end{array}$ \\
\hline Without Login & Is possible for basic formatting \\
\hline
\end{tabular}

Prototype 2.0 is focused on improvements in the application. In the second prototype, PHP7.3 programming language has been used. As it is the server language it is appropriate for this kind of app. It is a programming language which is used for interaction between the browser and the server, which should be a perfect option for this application development. Using PHP7.3 functions allows overwriting the XML code, thus are changing and modifying the e-materials formatting, updating them to another formatting for learner needs. 
\$zip = new ZipArchive;

\$filename_style = 'word/styles.xml';

\$filename = 'word/document.xml';

if(is_uploaded_file(\$_FILES["word-doc"]["tmp_name"]))\{

\$zip_tmp_name = \$_FILES["word-doc"]["tmp_name"];

\}else\{

\$zip_tmp_name = "EMPTY";

\}

\$zip_full_name = \$_FILES["word-doc"]["name"];

if(\$zip->open(\$zip_tmp_name)=== TRUE) \{

\$xml_string = \$zip->getFromName $(\$$ filename_style $)$;

\$xml = simplexml_load_string(\$xml_string);

Fig.2. The application code part

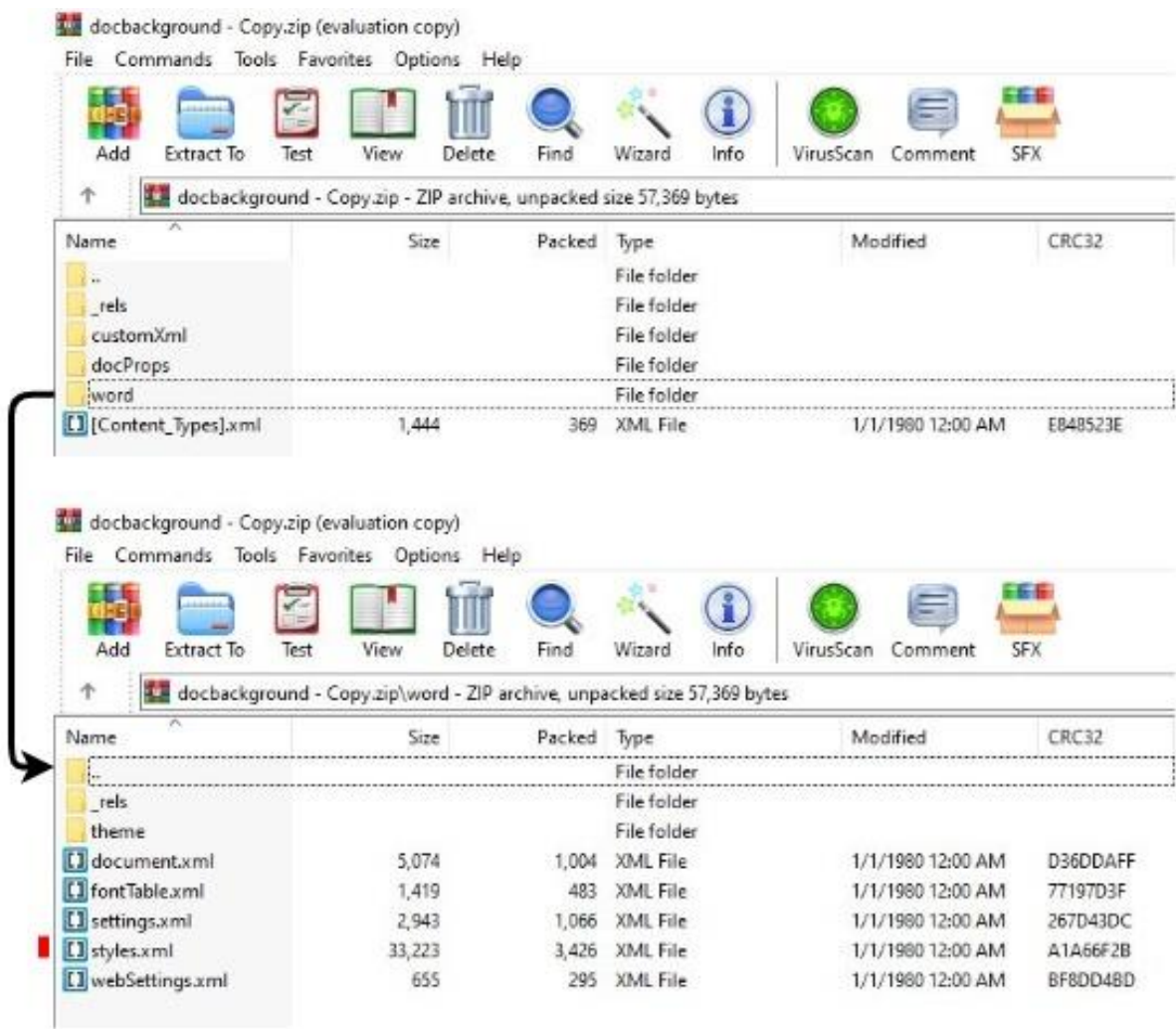

Fig.3. The ZipArchive and styles.xml 
The prototype 2.0 focus is to make it accessible and workable on all the most popular formats of e-materials.

MS Office Word document formats are one of the most popular e-material formats. To make the formatting of Word document, the first step - MS Word document should be renamed with *.zip extension. There is a need to make ZipArchive for extraction of file parts. Process definition and process is presented in application code part (Fig.2).

The received raw document is automatically converted into an archive, shrinks. Then the archive is being extracted ZipArchive contains all information about raw data. (Fig.3) and then application makes changes in MS Word content.

For document formatting, there is interest in file styles.xml which contain all necessary raw data of document existing formatting parameters and where changes after new requirements will be done.

This approach allows to make changes in parameters that are included in simple levels of personalization formatting as well as for more complicated levels. Complicated formatting levels include use of AI components to reach most individualized formatiing.

There is development of similar approach to use on other popular formats of ematerials.

\section{Conclusions and future work}

E-material formatting application, which improves the comfort of using e-material in learning and study process and decrease near work load by adapting on individual needs. It is based on developed recommendations for user-centric and adaptive educational ematerial creation and formatting.

Prototype 2.0 development is focused on improvement. PHP7.3 programming language is used as it is suitable for educational environments. Work on visual appearance in the application has been done.

During application development programmer meet several challenges. Several of them are related to version differences in document formats.

The system evaluation with users is a necessary future step. Currently, authors will be work on the improved version of the application and after the development of it are planned to make the Alpha test of the app with user-based testing. A correctly created prototype must give the possibility to conduct an alpha testing of the application in a larger user group.

\section{Aknowledgement}

The publication and presentation is made with the financial support of the project "Promotion of research, innovation and international cooperation in science at Liepaja University", Project No. 1.1.1.5/18/I/018. 


\section{References}

Findahl, O. (2014). The Swedes and the Internet. A yearly report from .SE (Internet Infrastructure Foundation) that maps change and development in internet use among the Swedish population: http://en.soi2014.se/

Khan, M., Khushdil (2013). Comprehensive Study on the Basis of Eye Blink, Suggesting Length of Text Line, Considering Typographical Variables the Way How to Improve Reading from Computer Screen," Advances in Internet of Things, Vol.3 No.1

Kretzschmar, F., Pleimling, D., Hosemann, J., Füssel, S. (2013). Subjective Impressions Do Not Mirror Online Reading Effort: Concurrent EEG-Eyetracking Evidence from the Reading of Books and Digital Media, https://journals.plos.org/plosone/article?id=10.1371/journal.pone. 0056178

Mackare K., Jansone A. (2017). Research of guidelines for designing e-study materials, Proceedings of the 11th International Scientific and Practical Conference Environment. Technology. Resources. June 15-17, 2017. Volume 2

Mackare, K., Jansone, A. (2019a) Personalized learning: effective e-material formatting for users without disability or specific limitation Educational Alternatives (ISSN 1314-7277), Volume 17, 2019, pp. 194-206 (RSCI, CNKI, PSB)

Mackare, K., Jansone, A. (2019b). The concept for e-material creating and formatting application prototype, Periodicals of Engineering and Natural Sciences (ISSN: 2303-4521).

Mackare, K., Jansone, A., Zigunovs, M. (2018). E-material Creating and Formatting Application. Advances in Intelligent Systems and Computing, 876, pp. 135-140.

Mackare, K., Jansone, A., Konarevs, I. (2019). The prototype version for e-material creating and formatting application, Baltic J. Modern Computing, Vol. 7(2019), No. 3, pp. 383-392.

Mangen, A, Walgermo, B R and Brønnick, K, Reading Linear Texts on Paper Versus Computer Screen: Effects on Reading Comprehension, International Journal of Educational Research, 2013, 58, 61-68;

Myrberg C., Wiberg N. (2015). Screen vs. paper: what is the difference for reading and learning?, Insights, 28(2).

Nielsen, J. (2000). Designing Web Usability: The Practice of Simplicity, New Riders Publishing, Indianapolis, 2000, p. 420.

Salmerón L., Strømsø. H. I., Kammerer, Y. (2018). Comprehension processes in digital reading. Available from: https://www.researchgate.net/publication/314371919_ Comprehension_processes_in_digital_reading

WEB (a). Report from We Are Social and Hootsuite "Global Digital Statshot Q3 2017", https://www.slideshare.net/wearesocialsg/digital-in-2017-global-overview

WEB (b). Statistics - Internet World Stats "WORLD INTERNET USAGE AND POPULATION STATISTICS 2020 Year-Q2 Estimates", https://www.internetworldstats.com/stats.htm

Webster, M. A. (2015). Visual Adaptation, Annual Review of Vision Science Vol. 1:547-567)

Zigunovs, M., Jansone, A., Mackare, K.(2018). E-learning material adaptive software development, In: Presentation of ICIC18, The 2nd International Conference of Innovation and Creativity (5-7 Apr. 2018, Liepaja, Latvia).

Received October 26, 2020, accepted November 21, 2020 